\title{
Structural Attributes of Organic Compounds for UV-Spectrophotometric Determination of Dissociation Constant-A Systematic Review
}

\author{
NEELAVENI THANGAVEL ${ }^{1 *}$, MOHAMMAD AL BRATTY1, HASSAN AL HAZMI"1, \\ ASIM NAJMI ${ }^{1}$ and DURGARAMANI SIVADASAN ${ }^{2}$
}

\begin{abstract}
1Department of Pharmaceutical Chemistry, College of Pharmacy, Jazan University, Saudi Arabia. ${ }^{2}$ Department of Pharmaceutics, College of Pharmacy, Jazan University, Saudi Arabia.

${ }^{*}$ Corresponding author E-mail: nchellappan@jazanu.edu.sa
\end{abstract}

http://dx.doi.org/10.13005/ojc/380110

(Received: January 15, 2022; Accepted: February 16, 2022)

ABSTRACT

UV-spectrophotometric determination of dissociation constant $\left(\mathrm{pK}_{\mathrm{a}}\right)$ is used routinely in various research fields. This review highlights the structural attributes of organic compounds that exhibit distinct $\mathrm{pH}$-sensitive UV-absorbance for ionized and unionized species qualifying for $\mathrm{pK}_{\mathrm{a}}$ measurement. Organic compounds must possess a double bond, the chromophore adjacent to the ionizing functional group. Compounds bearing up to five sigma bonds between the chromophore and ionizing group are eligible for UV-spectrophotometric determination of $\mathrm{pK}_{\mathrm{a}}$. This review serves as a quick guide for knowledge about structural requirements expediting $\mathrm{pK}_{\mathrm{a}}$ determination by UV-spectrophotometry. Besides, the study also identified the gap in research on $\mathrm{pK}_{\mathrm{a}}$ in drug discovery and food chemistry, revealing the necessity of determining $\mathrm{pK}_{\mathrm{a}}$ at the early stages of drug and food research to enhance the success rate in their development.

Keywords: Chromophore, Dissociation constant, Functional group, lonization, $\mathrm{pH}$, UV-spectrophotometry.

\section{INTRODUCTION}

The dissociation constant $\left(\mathrm{pK}_{\mathrm{a}}\right)$ is the $\mathrm{pH}$ at which there exists an equal proportion of ionized and unionized species of a compound or a drug. ${ }^{1}$ Knowledge about $\mathrm{pK}_{\mathrm{a}}$ values of chemical compounds is indispensable in organic chemistry, medicinal chemistry, analytical chemistry, biochemistry, food chemistry, apart from their applications in allied biological sciences. UV-spectrophotometric measurement of $\mathrm{pK}_{\mathrm{a}}$ affords efficient, simple, sensitive, and reliable pKa measurement at concentrations lower than micromoles. ${ }^{2}$ The choice of UV-spectrophotometry for $\mathrm{pK}_{\mathrm{a}}$ assessment depends on the chemical structures of compounds, especially an ionizing functional group adjacent to an organic moiety capable of UV absorbance known as the chromophore. Compounds display characteristic UV absorbance for unionized and ionized species on structural compliance. The ionization ratio depends on the $\mathrm{pH}$ of the solvent or medium used in the UV study. A plot of UV absorbance over the $\mathrm{pH}$ yields

This is an Open Access article licensed under a Creative Commons license: Attribution 4.0 International (CC- BY). Published by Oriental Scientific Publishing Company @ 2018

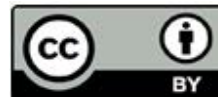


a sigmoidal curve usually, from which $\mathrm{pK}_{\mathrm{a}}$ could be calculated. ${ }^{1}$ Compounds possessing multiple ionizing groups can also display $\mathrm{pH}$-related shift of UV-spectrum at the distinct $\lambda_{\max }$ region enabling $\mathrm{pK}_{\mathrm{a}}$ determination, provided the ionizing groups exhibit significant variation in their molar absorptivity. ${ }^{3}$ Hence, substantial knowledge of the structural attributes of chemical compounds contributing to $\mathrm{pK}_{\mathrm{a}}$ determination by UV-spectrophotometry is essential to make it a time-effective method. Literature reviews that explored the theoretical background, significance, analytical methods, applications, factors affecting $\mathrm{pK}_{\mathrm{a}}$, and its measurement are available. No thought is public that delineates the structural attributes of organic compounds for UV-spectrophotometric determination of $\mathrm{pK}_{\mathrm{a}}$. Therefore, this systematic review aimed to analyze the structural characteristics of organic compounds for UV-spectrophotometric determination of $\mathrm{pK}_{\mathrm{a}}$.

\section{METHOD}

The literature review was conducted by customized search in "Google Scholar" using the search terms " $\mathrm{pK}_{\mathrm{a}}$ determination by UV spectrophotometry." A literature search was also achieved through "ScienceDirect" and "PubMed." Relevant data were retrieved from literature published during the years 2011-2021. Fifty-six articles were available, out of which 27 were excluded. The exclusion criteria included 1 book chapter, 4 review articles, $8 \mathrm{pK}_{\mathrm{a}}$ determination in non-aqueous solvents, and 14 analyses of inorganic compounds. Thus, data of experimental determination of $\mathrm{pK}_{\mathrm{a}}$ of organic compounds in aqueous buffers by UV spectrophotometry extracted from a total of 29 publications were utilized for systematic review. The flow chart for the systematic review method is shown in Figure 1.

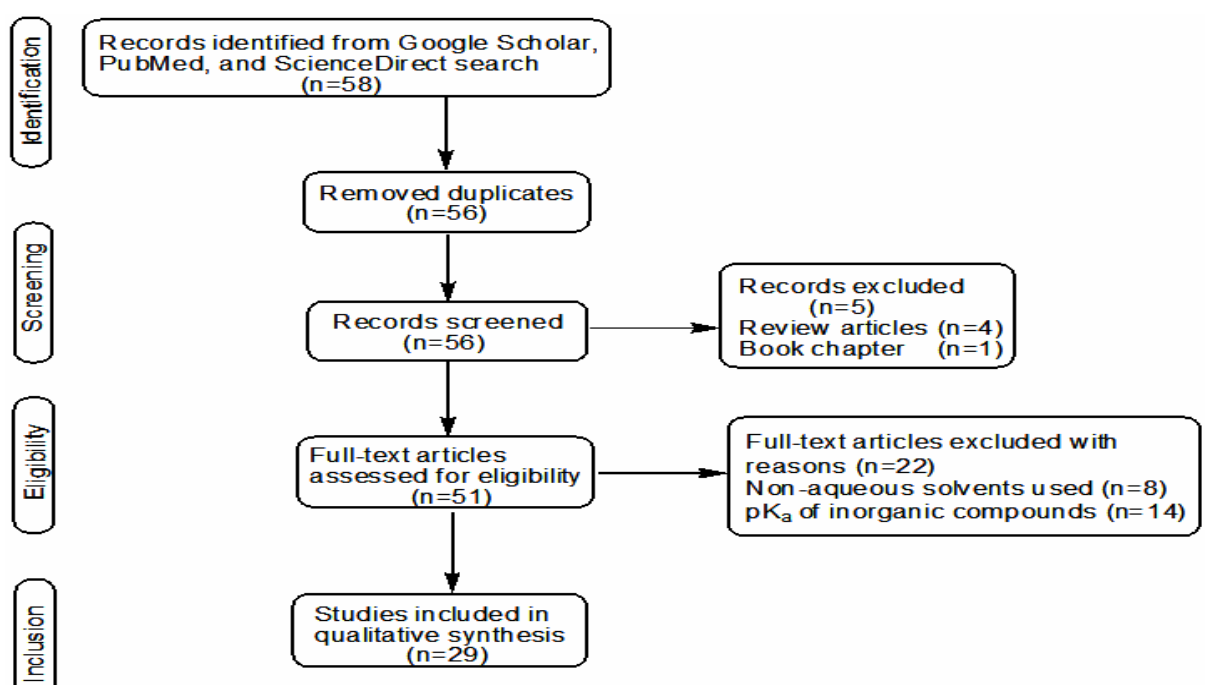

Fig. 1. Flow chart for the systematic review method

\section{RESULTS AND DISCUSSION}

\section{Dissociation Constant: A Pharmaceutical Perspective}

There exists a strong correlation between $\mathrm{pK}_{\mathrm{a}}$ and Lipinski's molecular descriptors. ${ }^{4}$ Almost all drug discovery and design studies quote the rule of five and report predicted molecular descriptors without focusing on $\mathrm{pK}_{\mathrm{a}}$. The drug's ionization status will decide the concentration of the polar form of the drug, which in turn will affect the partition coefficient and the solubility. $\mathrm{pK}_{\mathrm{a}}$ values can explain the extent of drug ionization and the nature of the contributing ion. Knowledge about experimental or predicted $\mathrm{pK}_{\mathrm{a}}$ is desirable at earlier stages of drug discovery to determine the rate of absorption, distribution, metabolism, and excretion (ADME) of lead/drug. ${ }^{5}$ This would enable scientists to optimize the chemical structure to exhibit better pharmacokinetic behaviour at changing $\mathrm{pH}$ of body compartments. Early determination assures the success of leading to a better drug after oral administration. It is more prudent to use $\mathrm{pK}_{\mathrm{a}}$ combined with other molecular properties to discover and optimize lead and formulate suitable dosage forms of drugs. One of the methods to improve the water solubility of the 
drug is to prepare their salt forms. The dissociation constant is the prime factor that decides whether the salt form will be energetically favorable in the acidic and basic $\mathrm{pH}$ of the stomach and intestine, respectively. $\mathrm{pK}_{\mathrm{a}}$ values of the parent drug and the salt derivative should be different such that there exist at least $2 \mathrm{pH}$ units difference between the two forms. ${ }^{6}$ The majority of drugs are either weak acids or bases. World drug index has $63 \%$ of drugs capable of ionization at the $\mathrm{pH}$ of 2 to 12 prevailing in various human body compartments. Among these ionizable drugs, $71.9 \%$ are monobasic or dibasic compounds, $14.6 \%$ are monoprotic or diprotic acids, whereas $7.5 \%$ are ampholytes with an acid and a basic function.

Acidic drugs with pKa less than 4 and basic drugs with $\mathrm{pK}_{\mathrm{a}}$ more than 12 may not enter the central nervous system due to their hydrophilic character. It is imperative to determine the $\mathrm{pK}_{\mathrm{a}}$ of drugs as early as possible in medicinal chemistry research. It is the critical determinant of absorption and partition of drugs across the blood-brain barrier and other biological compartments in the body. ${ }^{7}$ Knowledge of $\mathrm{pK}_{\mathrm{a}}$ of active pharmaceutical ingredients is essential in biopharmaceutics. Its application has been extended to assess the environmental contamination by pharmaceuticals, which has emerged as a potential contaminant from drug manufacturing industries. Apart from these known applications of $\mathrm{pK}_{\mathrm{a}}$, it is also helpful in separating and analysing acid-base drugs to standardize procedures like liquid chromatography and capillary electrophoresis for detection, isolation, and quantification of polarizable moieties. ${ }^{8}$

Though the significance of $\mathrm{pK}_{\mathrm{a}}$ is understood by researchers in medicinal chemistry, analytical chemistry, and the pharmaceutical industry, there is a gap in the experimental determination of dissociation constant values. Practical $\mathrm{pK}_{\mathrm{a}}$ values are timeconsuming to be determined either by a traditional or modern method. Moreover, it is a tedious process involving many samples handled at different $\mathrm{pH}$ values, and the output data is also significant in number. Hence researchers prefer to predict the $\mathrm{pK}_{\mathrm{a}}$ rather than its experimental determination. Range of software is available to predict dissociation constant values. The rise in publications related to predicted $\mathrm{pK}_{\mathrm{a}}$ indicates the convenience of predicting the values. ${ }^{9-12}$ These predictions depend on the nature and quality of data available and the number of similar compounds that software uses to identify possible ionization centers in the chemical structure of compounds under investigation. ${ }^{13-14} \mathrm{UV}$ spectrophotometry remains a viable option for $\mathrm{pK}_{\mathrm{a}}$ measurement.

\section{Categorizing the Field of Application}

Analysis of published works on $\mathrm{pK}_{\mathrm{a}}$ revealed that $50 \%$ of them was carried out as a part of drug discovery and development research in which UV method was used to determine the dissociation constant of new lead molecules, $18 \%$ of studies were aimed at determination of pKa by UV technique for existing drugs or natural products or dyes in the field of pharmaceutical analysis. In comparison, $29 \%$ of reports dealt with the ionization behaviour of organic compounds at different $\mathrm{pH}$ using the UV method, which we have classified under the field of applied analytical chemistry, and $3 \%$ of data was from the experiments related to food analysis. Table 1 shows information gained from the literature about the nature of compounds analyzed, ionizing groups present, and the field of application of $\mathrm{pK}_{\mathrm{a}}$. The results delineate the structural attributes of organic compounds essential for UV-spectrophotometric determination of $\mathrm{pK}_{\mathrm{a}}$.

\section{Structural Attributes of Organic Compounds}

Most organic compounds possess more than one ionizable functional group and may contain acid and base moieties. An organic compound may exist in different ionization forms based on the strength of the acid/base functional group and $\mathrm{pH}$ to which it is exposed. ${ }^{15}$ The extent of acid-base behaviour of the chemical is denoted by $\mathrm{K}_{\mathrm{a}}$, the ionization constant, synonymous with an acid dissociation constant or protonation constant. ${ }^{16}$ The exponential values of $\mathrm{K}_{\mathrm{a}}$ are challenging to handle; hence it is usual to convert to its negative log and written as:

$\mathrm{K}_{\mathrm{a}}=-\log \mathrm{pK}_{\mathrm{a}}$

If protonation status is considered, then $\mathrm{K}_{\mathrm{a}}$ is as follows:

$K_{a}=1 / K_{p}$

$\mathrm{pK}_{\mathrm{a}}=\log \mathrm{K}_{\mathrm{p}}$ 


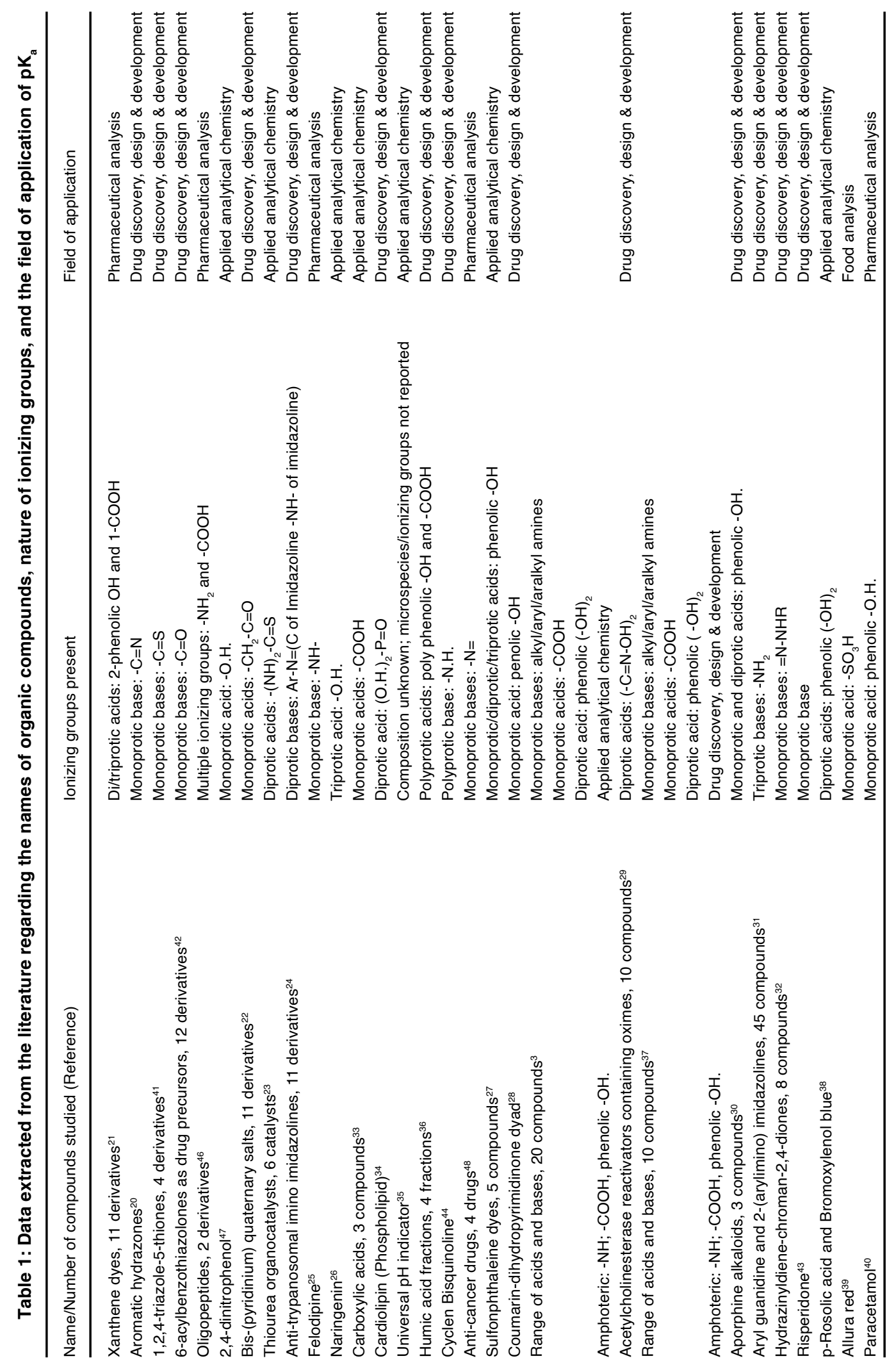


Drugs, organic compounds, or dyes are of interest to medicinal chemists and analytical chemists. These compounds may contain acidic functional groups like carboxylic acid, phenolic - $\mathrm{OH}$, enolic - $\mathrm{OH}$, sulfonic acid, sulphonamide, lactam, tetrazole ring, and basic functional groups like aromatic/aliphatic primary, secondary and tertiary amines. ${ }^{17}$ Acidic/basic groups present in drugs are ionizable at different $\mathrm{pH}$ and would determine the concentration of drug absorbed and distributed through lipophilic membranes. ${ }^{18} \mathrm{pK}_{\mathrm{a}}$ values of drugs lie in the range of 0 to $14 . .^{19}$ Lower the $\mathrm{pK}_{\mathrm{a}}$ stronger will be the acidic property and vice-versa.

Organic compounds require chromophores in their molecular structure to exhibit UV absorption. Predominant structural characteristic for the determination of $\mathrm{pK}_{\mathrm{a}}$ by UV spectrophotometry is the presence of an ionizable functional group adjacent to the chromophore, usually a double bond or conjugated system in drugs. Successful establishment of $\mathrm{pK}_{\mathrm{a}}$ value depends on the distance between the chromophore and the ionizing group. ${ }^{20}$

Figure 2 shows the chemical structures of xanthene dyes containing acidic groups near conjugated double bonds of the aromatic ring. ${ }^{21}$ Reported values of dissociation constants determined by UV-spectrophotometry of these xanthene dyes correlate to an ionizable phenolic hydroxyl group and a carboxylic acid group. The presence of electron-withdrawing atoms or groups like $-\mathrm{Br}$ or $-\mathrm{Cl}$ on the xanthene ring increased the acidity of the phenolic -OH group. The acidity of the carboxylic acid group was not much affected by the nature of the substituents. Structures in Fig. 3, successfully analysed for $\mathrm{pK}_{\mathrm{a}}$ values by UV method, include bis-(pyridinium)diquaternary salts, ${ }^{22}$ thiourea organocatalysts, ${ }^{23}$ imino imidazolines, ${ }^{24}$ Felodipine ${ }^{25}$ Naringenin, ${ }^{26}$ Sulphonphthaleine dyes, ${ }^{27}$ Coumarin dihydropyrimidinone dyad, ${ }^{28}$ Oximes, ${ }^{29}$ phenolic aporphine alkaloids, ${ }^{30}$ aryl guanidine, and arylimidazoline, ${ }^{31}$ Hydrazinyldienechroman-2,4-diones. ${ }^{32}$ All the abovementioned structures also possess chromophores adjacent to the ionizing group.

Acetic acid, Allura red, Aromatic hydrazones, Bromoxylenol blue, Cardiolipin, Doxorubicin, Humic acid, Paracetamol, Propionic acid, Rosolic acid, Thioguanine, and Vincristine, have the usual structural features of acids/bases near the chromophore..$^{20,33-40}$

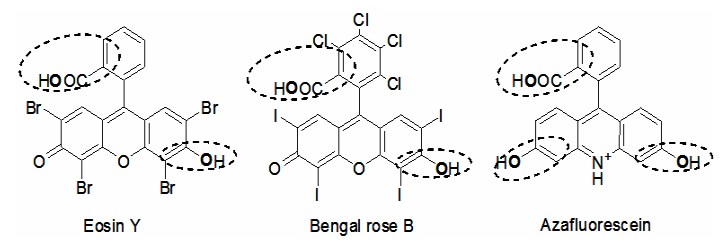

Fig. 2. Xanthene dyes with ionizable acidic groups proximal to a double bond. The ionizing atom is bold, and ellipses surround the distance to the chromophore

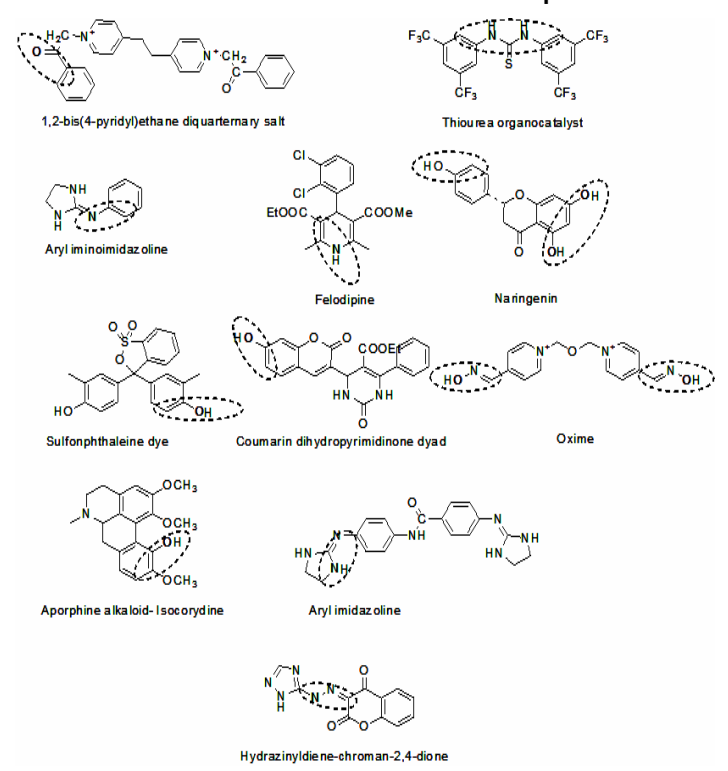

Fig. 3. Structural features of organic natural and synthetic compounds showing ionizing group adjacent to double bond chromophore

A protonation pattern deduced for 5-substituted derivatives of 4-phenyl-1,2,4-triazoline3-thione is shown in Fig. 4, suggesting that protonation occurs at sulfur atom at position $3 .{ }^{41}$. This study indicates that $\mathrm{pK}_{\mathrm{a}}$ of compounds possessing ionizable group two sigma bonds away from chromophore would also be sensitive to $\mathrm{pH}$ changes enabling its determination by UV spectrophotometry.

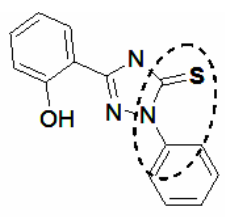

3-(2-hydroxyphenyl)-1-phenyl-1H1,2,4-triazole-5(4H)-thione

Fig. 4. Structure showing the ionization site two sigma bonds distal from the chromophore

A study has analyzed the dissociation behaviour of several 3,5-disubstituted-6-benzoyl 
benzothiazol-2-one represented in Fig. 5. ${ }^{42}$. This study revealed that the accurate evaluation of acid dissociation constants of compounds with protonation site three sigma bonds distal to conjugated double bonds is possible using the UV method. The oxygen atom of the 3-carboxamide functional group in its keto form underwent protonation at acidic $\mathrm{pH}$. UV spectrometric determination of $\mathrm{pK}_{\mathrm{a}}$ for risperidone in Fig. 5 also indicates that absorbance of structures with an ionizable group located three sigma bonds distal to chromophore would respond to small changes in $\mathrm{pH} .{ }^{43}$

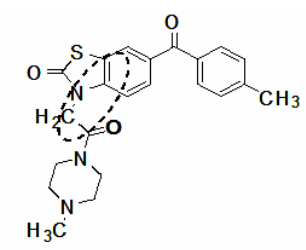

6-(4-m ethylbenzoyl)-3-

2-(4-methylpiperazin-1-yl)-

2-oxo ethyl)benzo[d] thiazol-2(3H)-one

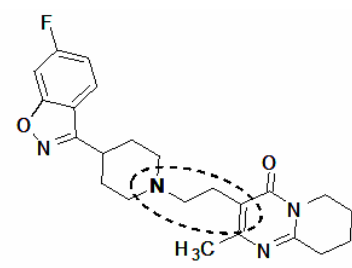

Fig. 5. Structures with three sigma bonds distance between the ionizing group and chromophore

3-phenyl-1-propylamine, 3-phenylpropanoic acid, and buspirone were compounds whose dissociation constants were established by the UV method, suggesting that structures containing four sigma bond distance between ionizing group and chromophore would be suitable for the UV method of $\mathrm{pK}_{\mathrm{a}}$ determination. ${ }^{3}$ The dissociation constant of Cyclen bisquinoline, a lead molecule for anti-malarial drugs, has four sigma bonds between an ionizable secondary amine and the double bond chromophore has been reported. ${ }^{44}$ Structures of buspirone and cyclen bisquinoline as representative molecules for this class are in Figure 6.
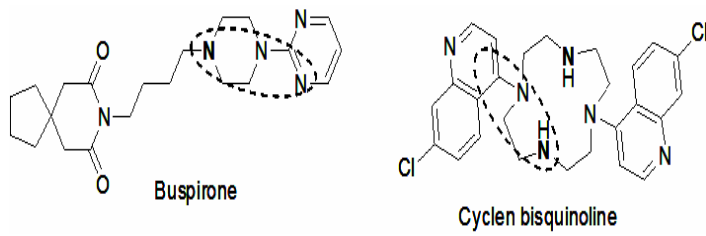

Fig. 6. Compounds having four sigma bonds between the ionizable group and chromophore

The above study has also proved that UV spectrophotometry is relevant for determining acidity/ dissociation constants of molecules possessing a five-sigma bond distance between the ionizing group and chromophore. ${ }^{3}$ Drugs like propranolol and diphenhydramine in Fig. 7 exemplify the abovementioned group.

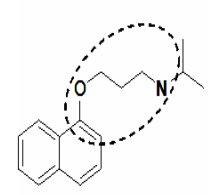

Propranolol

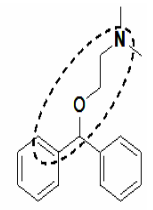

Diphenhydramine
Fig. 7. Drugs possessing ionizable group at a distance of five sigma bonds from the chromophore

Valsartan, an angiotensin II receptor blocker used for hypertension therapy, exhibits two $\mathrm{pK}_{\mathrm{a}}$ values determined by UV-spectrophotometry. Valsartan structure in Fig. 8 has an ionizable carboxylic acid group at a distance of four sigma bonds and an ionizable secondary amine in tetrazole ring two sigma bonds far from the chromophore. ${ }^{45}$

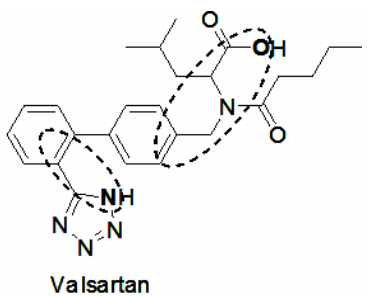

Fig. 8. Drug structure with multiple ionization sites

Improvisation of UV-spectrophotometry for high throughput screening of $\mathrm{pK}_{\mathrm{a}}$ by hyphenation with microtiter plates enables quick determination. ${ }^{24}$

\section{CONCLUSION}

Determination of the dissociation constant of organic compounds in different fields of chemical research is essential but tedious. The small number of research articles on $\mathrm{pK}_{\mathrm{a}}$ published in the past decade reveals the declined interest and focus on the critical physicochemical parameter of organic compounds. Extensive studies on $\mathrm{pK}_{\mathrm{a}}$ values of drugs and food at the initial stages of development are necessary for an enhanced success rate. UV-spectrophotometry is a reliable and sensitive method for determining $\mathrm{pK}_{\mathrm{a}}$. A detailed understanding of the structural attributes of organic compounds for UV-spectrophotometric determination of dissociation constant can expedite the process. Organic compounds possessing ionizing functional groups at a distance of a maximum of five sigma bonds from the chromophore are sensitive to $\mathrm{pH}$ changes. Their $\mathrm{pK}_{\mathrm{a}}$ can be measured accurately using UVspectrophotometry. Compounds with multiple ionization sites exhibiting multiple $\mathrm{pK}_{\mathrm{a}}$ values also follow the same structural rule. 
This review report emphasizes the essential knowledge of structural characteristics of organic drugs, pharmaceuticals, and food products to determine the dissociation constant by the UV-spectrophotometric method. Future research must focus on describing the structural features of organic compounds concerning the UV-spectrophotometric determination of dissociation constant. The steer to analyze dissociation constants by UV-spectrophotometry of organic compounds having chromophores farther from the ionizing groups is set forth by this study.

\section{ACKNOWLEDGMENT}

The authors thank Jazan University for providing easy access to the Saudi Digital Library facilitating literature retrieval.

\section{Conflicts of Interest}

None, declared.

\section{REFERENCES}

1. Berkhout, JH.; Ram,A.;H. RecentAdvancements in Spectrophotometric $\mathrm{pK}_{\mathrm{a}}$ Determinations: A Review. Indian Journal of Pharmaceutical Education and Research., 2019, 53(4s), S475-S480.10.5530/ijper. 53. 4s.141.

2. Reijenga, J.; Van Hoof, A.; Van Loon, A.; Teunissen, B. Development of methods for the determination of pKa values. Analytical Chemistry Insights., 2013, 8, 53-71. 10.4137/ ACl.S12304

3. Dohoda, D.; Tsinman, K.; Tsinman, O.; Wang, H.; Tam, K.Y. Spectrophotometric $\mathrm{pK}_{\mathrm{a}}$ determination of ionizable pharmaceuticals: Resolution of molecules with weak $\mathrm{pH}$ dependent spectral shift. Journal of Pharmaceutical and Biomedical Analysis., 2015, 114, 88-96. 10.1016/j.jpba.2015.05.009.

4. Manallack, D.T.; Yuriev, E.; Chalmers. DT. The influence and manipulation of acid/ base properties in drug. Drug Discovery Today:Technologies., 2018, 27, 41-47. https:// doi.org/10.1016/j.ddtec.2018.04.003.

5. Darnoville, C. Automated techniques in pKa determination: Low, medium and highthroughput screening methods. Drug Discovery Today:Technologies., 2018, 27, 49-58. https:// doi.org/10.1016/j.ddtec. 2018. 04.001.

6. Makary, P. Principles of Salt Formation. UKJ Pharmaceutical \& Biosciences., 2014, 2(4), 1-3. 10.20510/UKJPB/2//4/91101.

7. Mtewa, A.G.; Ngwira, K.; Lampiao. F.; Weisheit, A.; Tol, C.U.; Ogwang,P.E.; Sesaazi, C.D. Fundamental Methods in Drug Permeability, $\mathrm{pK}_{\mathrm{a}}$, LogP and LogDx Determination. Journal of Drug Research and Development., 2018, 4(2). dx.doi.org/10. 16966/2470-1009.146.

8. Pathare, B.; Tambe,V.; Patil, V. A review on various analytical methods used in determination of dissociation constant.
International Journal of Pharmacy and Pharmaceutical Sciences., 2014, 6(8), 26-34. https://innovareacademics.in/journals/index. php/ijpps/article/view/1641.

9. Jensen, J.H.; Swain, C.J.; Olsen, L. Prediction of $\mathrm{p} \mathrm{K}$ a Values for Druglike Molecules Using Semiempirical Quantum Chemical Methods. The Journal of Physical Chemistry A., 2017, 121(3), 699-707. https://doi.org/10.1021/acs. jpca.6b10990.

10. Kromann, J.C.; Larsen, F.; Moustafa, H.; Jensen, J.H. Prediction of pKa values using the PM6 semiempirical method. PeerJ., 2016, 4, e2335. 10.7717/peerj.2335.

11. Balogh, G.T.; Tarcsay, Á.; Keserű, G.M. Comparative evaluation of $\mathrm{pK}$ a prediction tools on a drug discovery dataset. Journal of Pharmaceutical and Biomedical Analysis., 2012, 67, 63-70. 10.1016/j.jpba.2012.04.021.

12. Liton, M.A.K.; Salma, U.; Hossain, M.B. Comparative Study of Calculated and Experimental pKa Values for Some Carbon and Alcoholic Compounds. American Journal of Chemistry., 2013, 3(3), 37-43. 10.5923/j. chemistry.20130303.01.

13. Machuqueiro, M.; Baptista, A.M. Is the prediction of $\mathrm{pKa}$ values by constant-pH molecular dynamics being hindered by inherited problems? Proteins: Structure, Function, and Bioinformatics., 2011, 79(12), 3437-3447.10.1002/prot.23115.

14. Rupp, M.; Korner, R.; V Tetko, I. Predicting the $\mathrm{pK}_{\mathrm{a}}$ of small molecules. Combinatorial Chemistry \& High Throughput Screening., 2011, 14(5), 307-327. 10.2174/ 138620711795508403.

15. Kamel, M.M.; Syam, Y.M. Structure and physicochemical properties in relation to drug action. Egyptian Pharmaceutical Journal., 2013, 12(2), 95.10.4103/1687-4315.124000 
16. Carvalho, F.M.; de Oliveira Só, Y.A.; Wernik, A.S.K.; Silva, M.A.; Gargano, R. Accurate acid dissociation constant $\left(\mathrm{pK}_{\mathrm{a}}\right)$ calculation for the sulfachloropyridazine and similar molecules. Journal of Molecular Modeling., 2021, 27(8), 233.10.1007/s00894-021-04851-9.

17. Maslehat, S.; Sardari, S.; Arjenaki. Frequency and Importance of Six Functional Groups that Play A Role in Drug Discovery. Biosciences Biotchnology Research Asia., 2018, 15(3). http://dx.doi.org/10.13005/bbra/2659.

18. Manallack, D.T.; Prankerd, R.J.; Yuriev, E.; Oprea, T.I.; Chalmers, D.K. The significance of acid/base properties in drug discovery. Chemical Society Reviews., 2013, 42(2), 485-496.10.1039/c2cs35348b.

19. Charifson, P.S.; Walters, W.P. Acidic and basic drugs in medicinal chemistry: a perspective. Journal of Medicinal Chemistry., 2014, 57(23), 9701-9717.https://doi.org/10.1021/ jm501000a.

20. Jankulovska, M.S.; Spirevska, I.; Dimova, V. UV Spectrophotometric Determination of Thermodynamic Dissociation Constants of Some Aromatic Hydrazones in Acid Media. Journal of the Mexican Chemical Society., 2020, 63(4).https://doi.org/10.29356/jmcs.v63i4.794.

21. Batistela, V.R.; Pellosi, D.S.; de Souza, F.D.; da Costa, W.F.; de Oliveira Santin, S.M.; de Souza, V.R.; Caetano, W.; de Oliveira, H.P.M.; Scarminio, I.S.; Hioka, N. pKa determinations of xanthene derivates in aqueous solutions by multivariate analysis applied to UV-Vis spectrophotometric data. Spectrochimica Acta Part A: Molecular and Biomolecular Spectroscopy., 2011, 79(5), 889-897. 10.1016/j.saa.2011.03.027.

22. Furdui, B.; Dinica, R.M.; Tabacaru, A.; Pettinari, C. Synthesis and physico-chemical properties of a novel series of aromatic electron acceptors based on $\mathrm{N}$-heterocycles. Tetrahedron., 2012, 68(31), 6164-6168. 10.1016/j.tet.2012.05.077.

23. Jakab, G.;Tancon, C.; Zhang, Z.; Lippert, K.M.; Schreiner, P.R. (Thio) urea organocatalyst equilibrium acidities in DMSO. Organic Letters., 2012, 14(7), 1724-1727. https://doi. org/10.1021/ol300307c.

24. Martínez, C.H.R.; Dardonville, C. Rapid Determination of lonization Constants $(\mathrm{p} \mathrm{Ka})$ by UV Spectroscopy Using 96-Well Microtiter
Plates. ACS Medicinal Chemistry Letters., 2012, 4(1), 142-145. https://doi.org/10.1021/ $\mathrm{ml} 300326 \mathrm{v}$.

25. Pandey, M.; Jaipal, A.; Kumar, A.; Malik, R.; Charde, S., Determination of pKa of felodipine using UV-Visible spectroscopy. Spectrochimica Acta Part A: Molecular and Biomolecular Spectroscopy., 2013, 115, 887-890. https://doi.org/10.1016/j. saa.2013.07.001.

26. Farajtabar, A.; Gharib, F. Spectral analysis of naringenin deprotonation in aqueous ethanol solutions. Chemical Papers., 2013, 67(5), 538-545. 10.2478/s11696-013-0309-9.

27. De Meyer, T.; Hemelsoet, K.; Van Speybroeck, V.; De Clerck, K. Substituent effects on absorption spectra of $\mathrm{pH}$ indicators: An experimental and computational study of sulfonphthaleine dyes. Dyes and Pigments., 2014, 102, 241-250. https://doi.org/10.1016/j. dyepig.2013.10.048.

28. Vitório, F.; Pereira, T.M.; Castro, R.N.; Guedes, G.P.; Graebin, C.S.; Kümmerle, A.E. Synthesis and mechanism of novel fluorescent coumarindihydropyrimidinone dyads obtained by the Biginelli multicomponent reaction. New Journal of Chemistry., 2015, 39(3), 2323-2332. https://doi.org/10.1039/C4NJ02155J.

29. Musil, K.; Florianova, V.; Bucek, P.; Dohnal, V.; Kuca, K.; Musilek, K. Development and validation of a FIA/UV-vis method for pKa determination of oxime based acetylcholinesterase reactivators. Journal of Pharmaceutical and Biomedical Analysis., 2016, 117, 240-246. https://doi. org/10.1016/j.jpba.2015.09.010.

30. Zahari, A.; Ablat, A.; Omer, N.; Nafiah, M.A.; Sivasothy, Y.; Mohamad, J.; Khan, M.N.; Awang, K. Ultraviolet-visible study on acidbase equilibria of aporphine alkaloids with antiplasmodial and antioxidant activities from Alseodaphne corneri and Dehaasia longipedicellata. Scientific Reports., 2016, 6, 21517. 10.1038/srep21517.

31. Dardonville, C.; Caine, B.A.; de la Fuente, M.N.; Herranz, GM; Mariblanca, B.C.; Popelier, P.L. Substituent effects on the basicity $\left(\mathrm{pK}_{\mathrm{a}}\right)$ of aryl guanidines and 2-(arylimino) imidazolidines: correlations of $\mathrm{pH}$-metric and UV-metric values with predictions from gasphase ab initio bond lengths. New Journal of Chemistry., 2017, 41(19), 11016-11028. https://doi.org/10.1039/C7NJ02497E. 
32. Ballazhi, L.; Imeri, F.; Jashari, A.; Popovski, E.; Stojkovic, G.; Dimovski, A.J.; Mikhova, B.; Mladenovska, K. Hydrazinyldiene-chroman-2, 4-diones in inducing growth arrest and apoptosis in breast cancer cells: Synergism with doxorubicin and correlation with physicochemical properties. Acta Pharmaceutica., 2017, 67(1), 35-52.10.1515/acph-2017-0006.

33. Shukla, S.K.; Kumar, A. Probing the acidity of carboxylic acids in protic ionic liquids, water, and their binary mixtures: activation energy of proton transfer. The Journal of Physical Chemistry B., 2013, 117(8), 2456-2465. https://doi.org/10.1021/jp310927w.

34. Olofsson, G.; Sparr, E. Ionization constants $\mathrm{pK}_{\mathrm{a}}$ of cardiolipin. PloS One., 2013, 8(9), e73040. https://doi.org/10.1371/journal. pone.0073040.

35. Salgado, L.V.; Vargas-Hernández, C. Spectrophotometric determination of the pKa, isosbestic point and equation of absorbance vs. $\mathrm{pH}$ for a universal $\mathrm{pH}$ indicator. American Journal of Analytical Chemistry., 2014, 5(17), 1290. 10.4236/ajac.2014.517135.

36. Klučáková, M.; Kolajová, R. Dissociation ability of humic acids: Spectroscopic determination of pKa and comparison with multi-step mechanism. Reactive and Functional Polymers., 2014, 78, 1-6. https://doi. org/10.1016/j.reactfunctpolym.2014.02.005.

37. S Bharate, S.; Kumar, V.; A Vishwakarma, $R$. Determining partition coefficient $(\log P)$, distribution coefficient ( $\log \mathrm{D})$ and ionization constant $\left(\mathrm{pK}_{\mathrm{a}}\right)$ in early drug discovery. Combinatorial Chemistry \& High Throughput Screening., 2016, 19(6), 461-469. 10.2174/1 386207319666160502123917.

38. Shokrollahi, A.; Gohari, M.; Ebrahimi, F. Determination of Acidity Constants of $\mathrm{p}$-Rosolic acid and Bromoxylenol Blue by Solution Scanometric Method. Analytical and Bioanalytical Chemistry Research., 2018, 5(1), 67-79. 10.22036/ABCR.2017.89026.1153.

39. Dinç, E.; Ertekin, Z.C.; Ünal, N. Three-way analysis of $\mathrm{pH}-\mathrm{UV}$ absorbance dataset for the determination of paracetamol and its pKa value in presence of excipients. Spectrochimica Acta Part A: Molecular and Biomolecular Spectroscop.y., 2020, 230, 118049. 10.1016/j.saa.2020.118049.

40. Dinç, E.; Ünal, N.; Ertekin, Z.C. Three-way analysis-based $\mathrm{pH}-\mathrm{UV}$-Vis spectroscopy for quantifying allura red in an energy drink and determining colorant's pKa. Journal of Food \& Drug Analysis., 2021, 29(1), 76-86. https:// doi.org/10.38212/2224-6614.1275.

41. Dimova, V. A study of behavior of some 5-substituted-4-phenyl-1, 2, 4-triazoline3-thiones in sulfuric acid solution using characteristic vector analysis. Turkish Journal of Chemistry., 2011, 35(1), 109-120. https://journals.tubitak.gov.tr/chem/abstract. $\mathrm{htm}$ ?id=11441.

42. Gülseven Sıdır, Y.; Sıdır, I.; Berber, H. Spectroscopic determination of acid dissociation constants of $\mathrm{N}$-substituted-6acylbenzothiazolone derivatives. The Journal of Physical Chemistry A., 2011, 115(20), 5112-5117.10.1021/jp2018549.

43. Dubey, S.K.; Singhvi, G.; Tyagi, A.; Agarwal, H.; Krishna, K. Spectrophotometric Determination of pKa and Log P of Risperidone. Journal of Applied Pharmaceutical Science., 2017, 7(11), 155-158. 10.7324/JAPS.2017.71123.

44. Hossain, M.F.; Shrestha, A.; Khan, M.F. UVMetric, pH-Metric and RP-HPLC Methods to Evaluate the Multiple pKa Values of a Polyprotic Basic Novel Antimalarial Drug Lead, Cyclen Bisquinoline. Modern Chemistry \& Applications., 2014, 2(4). 10.4172/23296798.1000145.

45. Meloun, M.; Pilařová, L.; Pfeiferová, A.; Pekárek, T. Method of UV-Metric and $\mathrm{pH}$-Metric Determination of Dissociation Constants of Ionizable Drugs: Valsartan. Journal of Solution Chemistry., 2019, 48(8), 1266-1286. https://doi.org/10.1007/s10953019-00913-y. 